\title{
Identification of actinomycetes from plant rhizospheric soils with inhibitory activity against Colletotrichum spp., the causative agent of anthracnose disease
}

Bungonsiri Intra ${ }^{1,2,3}$, Isada Mungsuntisuk $k^{1,2}$, Takuya Nihira ${ }^{2,4}$, Yasuhiro Igarashi ${ }^{5}$ and Watanalai Panbangred ${ }^{1,2,3^{*}}$

\begin{abstract}
Background: Colletotrichum is one of the most widespread and important genus of plant pathogenic fungi worldwide. Various species of Colletotrichum are the causative agents of anthracnose disease in plants, which is a severe problem to agricultural crops particularly in Thailand. These phytopathogens are usually controlled using chemicals; however, the use of these agents can lead to environmental pollution. Potential non-chemical control strategies for anthracnose disease include the use of bacteria capable of producing anti-fungal compounds such as actinomycetes spp., that comprise a large group of filamentous, Gram positive bacteria from soil. The aim of this study was to isolate actinomycetes capable of inhibiting the growth of Colletotrichum spp, and to analyze the diversity of actinomycetes from plant rhizospheric soil.

Results: A total of 304 actinomycetes were isolated and tested for their inhibitory activity against Colletotrichum gloeosporioides strains DoA d0762 and DoA c1060 and Colletotrichum capsici strain DoA c1511 which cause anthracnose disease as well as the non-pathogenic Saccharomyces cerevisiae strain IFO 10217. Most isolates (222 out of 304, 73.0\%) were active against at least one indicator fungus or yeast. Fifty four (17.8\%) were active against three anthracnose fungi and 17 (5.6\%) could inhibit the growth of all three fungi and S. cerevisiae used in the test. Detailed analysis on 30 selected isolates from an orchard at Chanthaburi using the comparison of 16S rRNA gene sequences revealed that most of the isolates (87\%) belong to the genus Streptomyces sp., while one each belongs to Saccharopolyspora (strain SB-2) and Nocardiopsis (strain CM-2) and two to Nocardia (strains BP-3 and LK-1). Strains LC-1, LC-4, JF-1, SC-1 and MG-1 exerted high inhibitory activity against all three anthracnose fungi and yeast. In addition, the organic solvent extracts prepared from these five strains inhibited conidial growth of the three indicator fungi. Preliminary analysis of crude extracts by high performance liquid chromatography (HPLC) indicated that the sample from strain JF-1 may contain a novel compound. Phylogenetic analysis revealed that this strain is closely related to Streptomyces cavurensis NRRL 2740 with 99.8\% DNA homology of 16S rRNA gene (500 bp).

Conclusion: The present study suggests that rhizospheric soil is an attractive source for the discovery of a large number of actinomycetes with activity against Colletotrichum spp. An interesting strain (JF-1) with high inhibitory activity has the potential to produce a new compound that may be useful in the control of Colletotrichum spp.
\end{abstract}

\footnotetext{
* Correspondence: scwpb@mahidol.ac.th

'Department of Biotechnology, Faculty of Science, Mahidol University,

Bangkok 10400, Thailand

Full list of author information is available at the end of the article
} 


\section{Background}

Anthracnose disease caused by species of Colletotrichum is one of the most economically important plant diseases and is responsible for reducing the marketable yield of crop production ( $10 \%$ to $80 \%$ reduction) in some developing countries such as Thailand, Pakistan, Turkey and Mexico [1,2]. Colletotrichum spp. can cause anthracnose disease in fruits such as avocado, guava, papaya, mango and passion fruit [3]. Two significant Colletotrichum species found in Thailand are C. capsici and C. gloeosporioides and these same pathogens are also the main phytopathogens in South America and Asia, especially tropical regions of Asia [4]. C. capsici generally infects mature fruit, while C.gloeosporioides infects both green and mature fruits [4].

Although phytopathogens are usually suppressed using synthetic chemicals, the excessive use of chemical control has led to environmental pollution. Moreover, the efficiency of these pesticides is continually decreasing due to the development of resistant pathogens. Over the last 25-30 years, improvement of alternative control methods, including the use of microorganisms, has been undertaken [4]. Most biological controls are directed toward wound pathogens and involve the use of antagonistic bacteria that produce antibiotics [5-7].

Actinomycetes, particularly Streptomyces species are among the richest sources of antibiotics [8-10]. Roughly $60 \%$ of biologically active compounds that have been developed for agricultural use originated from Streptomyces [11]. Various groups of bioactive compounds such as macrolide, benzoquinones [12], aminoglycosides $[13,14]$, polyenes $[15,16]$, and nucleoside antibiotics $[17,18]$ are examples of agriculturally useful metabolites produced from Streptomyces.

In order to find bioactive compounds that may be useful in the control of fungal pathogens, such as Colletotrichum spp., we isolated actinomycetes species and screened them for antifungal activity. Of the actinomycetes isolated, 30 selected strains were also subjected to phylogenetic analysis using comparison of their $16 \mathrm{~S}$ rRNA gene sequences to investigate the diversity of actinomycetes in rhizospheric soil collected from orchards.

\section{Results and Discussion}

\section{Isolation of actinomycetes}

A total of 304 actinomycetes isolates were obtained from 39 rhizospheric soil samples collected from orchards in Chanthaburi, Bangkok, Petchaburi, and Nongbualamphu provinces. The collection areas included the eastern, central and northeastern parts of Thailand. Rhizospheric soil was selected for use in this study since rhizosphere-associated soils can contain almost twice as many actinomycetes isolates as non-rhizosphere-associated soils, according to a previous report by Crawford and co-workers [19].
Initially, isolated colonies had a smooth appearance but later developed a weft of aerial mycelium that either appeared floccose, granular, powdery or velvety as described in Bergey's Manual of Determinative Bacteriology [20]. Colonies of actinomycetes, in particular those of Streptomyces species, were picked on the basis of their morphological characteristics on agar plates. The Streptomyces colonies can be easily identified by their opaque, rough, nonspreading morphology and are usually embedded resulting in adherence to agar medium. The color of substrate and aerial mycelia was variable; however, almost any colony gave an earthy odor that is characteristic of Streptomyces.

\section{Antimicrobial activity of actinomycete isolates}

Among the 304 actinomycetes isolates, 214 (70.4\%), 110 (36.2\%), 64 (21.1\%), 42 (13.8\%) displayed activity against the growth of C. gloeosporioides strains DoA d0762 and DoA c1060, C. capsici strain DoA c1511 and S. cerevisiae strain IFO 10217, respectively. Two hundred and twenty two isolates (73.0\%) were active against at least one indicator microorganism. Inhibition toward C. gloeosporioides strain DoA d0762 was shown by 214 isolates, and inhibition toward C. capsici strain DoA c1511 was shown by 64 isolates. Fifty four strains (17.8\%) inhibited all of three fungi which caused anthracnose disease. Only 17 isolates (5.6\%) inhibited all indicator fungi as well as yeast. The use of several indicator microorganisms helped to select strains with potent activity [11,17]. Antifungal activity of the 304 actinomycete isolates is summarized in Table 1 .

\section{Molecular phylogeny of the 30 selected isolates based on 165 rRNA gene}

To assess the actinobacterial diversity in rhizospheric soils from orchards, 30 isolates from a Chanthaburi orchard were selected for additional analysis. The orchard contains several types of fruit trees including rambutan, jack fruit, longkong, lychee, and salak. The orchard was selected due to the variety of fruit trees since differences in tree and fruit materials can affect diversity of the soil microbes [21-23]. The nucleotide sequences for a section of the $16 \mathrm{~S}$ rRNA gene (500 bp) from the 30 selected strains (GenBank Accession numbers GU13002-GU130031) were subjected to BLASTN analysis using the NCBI database for identification at the genus level. All 30 isolates contained different nucleotide sequences for the 16S rRNA gene, indicating that they were different strains (data not shown). Of the actinomycetes tested 26 out of 30 strains belonged to genus Streptomyces and contained between 95-100\% DNA homology in the 16S rRNA gene. Two strains (strains BP-3 and LK-1) had shown proximity to genus Nocardia. Strains SB-2 and CM-2 belong to genera Saccharopolyspora and Nocardiopsis, respectively 
Table 1 Summary of antifungal activity of the 304 actinomycete isolates by the co-culture method

\begin{tabular}{cccccccccccc}
\hline \multicolumn{10}{c}{ Total number of isolated strains against indicator fungi } \\
\hline $\mathbf{A}^{*}$ & $\mathbf{B}^{*}$ & $\mathbf{C}^{*}$ & $\mathbf{D}^{*}$ & $\mathbf{A}+\mathbf{B}$ & $\mathbf{A}+\mathbf{C}$ & $\mathbf{A}+\mathbf{D}$ & $\mathbf{B}+\mathbf{C}$ & $\mathbf{B}+\mathbf{D}$ & $\mathbf{C}+\mathbf{D}$ & $\mathbf{A}+\mathbf{B}+\mathbf{C}$ & $\mathbf{A}+\mathbf{B}+\mathbf{C}+\mathbf{D}$ \\
\hline 214 & 110 & 64 & 42 & 109 & 59 & 35 & 58 & 25 & 19 & 54 & 17 \\
$70.4 \%$ & $36.2 \%$ & $21.1 \%$ & $13.8 \%$ & $35.9 \%$ & $19.4 \%$ & $11.5 \%$ & $19.1 \%$ & $8.2 \%$ & $6.3 \%$ & $17.8 \%$ & $5.6 \%$ \\
\hline
\end{tabular}

${ }^{*} \mathrm{~A}$ is C. gloeosporioides strain DoA d0762; B is C. gloeosporioides strain DoA c1060; C is C. capsici strain DoA c1511 and D is Saccharomyces cerevisiae strain IFO10217.

(Table 2). The prevalence of Streptomyces species over other actinomycetes was likely due to screening conditions (media and cultivation). Pridham and water proline agar media used in this study are preferred by Streptomyces [24].

The results described above were supported by phylogenetic analysis based on the neighbor-joining tree. The 30 isolates were sorted into 4 main clusters with highest similarity to the genera Streptomyces, Saccharopolyspora, Nocardia and Nocardiopsis, respectively (Figure 1). The
BP-3 and LK-1 isolates matched with high sequence identity to members of the Nocardia cyriacigeorgica clade, while SB-2 and CM-2 isolates were closely related to Saccharopolysporaterberi R40 and Nocardiopsis sp. 94N10-1 clade members, respectively. Most of the selected isolates (26 strains) were closely matched to Streptomyces spp. Our results suggest that actinomycetes in plant rhizospheric soils from orchards are diverse and that these strains are suitable for natural product screening.

Table 2 Antifungal activity of $\mathbf{3 0}$ actinomycete isolates obtained from rhizospheric soil samples in Chanthaburi

\begin{tabular}{|c|c|c|c|}
\hline Soil samples collected under & Designated number & Closely related strain* & Antifungal activity** \\
\hline Rambutan & RB-1 & S. longisporus strain: NBRC 12885 (AB184219.1) & A \\
\hline \multirow[t]{3}{*}{ Black pepper } & $\mathrm{BP}-1$ & S. bikiniensis strain WANG-1 (EU560974.1) & - \\
\hline & $\mathrm{BP}-2$ & Streptomyces sp. MJM5732 (EU603355.1) & $A+B$ \\
\hline & $\mathrm{BP}-3$ & Nocardia araoensis strain DSM 44729 isolate VNS41 (AY903623.1) & $A+B$ \\
\hline Longkong & LK-1 & Nocardia thailandica (AB126874.1) & $A+B$ \\
\hline \multirow[t]{4}{*}{ Lychee } & LC-1 & S. griseocarneus strain: NBRC 13428 (AB184863.1) & $A+B+C+D$ \\
\hline & LC-2 & S. spororaveus strain HBUM174519 (EU77063.1) & $A+B$ \\
\hline & LC-3 & S. lavendulae strain IFO 3125 (D85106.1) & $\mathrm{D}$ \\
\hline & LC-4 & S. herbaricolor strain NRRL B-3299T (DQ442505.2) & $A+B+C+D$ \\
\hline \multirow[t]{2}{*}{ Leech lime } & LL-1 & Streptomyces sp. 210726 (EU600089.1) & - \\
\hline & $\mathrm{LL}-2$ & Streptomyces sp. A00032 (EF690247.1) & - \\
\hline \multirow[t]{2}{*}{ Cumin } & $\mathrm{CM}-1$ & S. antibioticus strain: NBRC 13271 (AB184340.1) & A \\
\hline & $\mathrm{CM}-2$ & Nocardiopsis sp. 94N10-1 (EU196477.1) & $A+B$ \\
\hline Jack fruit & $J F-1$ & S. cavourensis subsp. cavourensis strain NRRL 2740 (DQ445791.1) & $A+B+C+D$ \\
\hline Siam cardamom & SC-1 & S. triostinicus strain CKM7 (EU635725.1) & $A+B+C+D$ \\
\hline Dragon fruit & DF-1 & S. collinus subsp. albescens strain NBRC 12547 (AB184101.2) & A \\
\hline \multirow[t]{5}{*}{ Pisang mas } & PM-1 & S. aureus strain HBUM174596 (EU841581) & A \\
\hline & PM-2 & S. roseocinereus isolate S55-4 (EU521698.1) & $A+B$ \\
\hline & $\mathrm{PM}-3$ & S. roseocinereus isolate S55-4 (EU521698.1) & $A+B$ \\
\hline & PM-4 & S. setonensis strain NBRC 13797 (AB184488.1) & - \\
\hline & PM-5 & S. cinnamocastaneus strain HBUM173422 (EU841658) & A \\
\hline \multirow[t]{2}{*}{ Tamarind } & TM-1 & S. pseudovenezuelae strain IMER-B1-8 (FJ796459.1) & - \\
\hline & $\mathrm{TM}-2$ & S. pseudovenezuelae strain IMER-B1-8 (FJ796459.1) & A \\
\hline \multirow[t]{2}{*}{ Sapodilla } & SP-1 & S. triostinicus strain CKM7 (EU635725.1) & $A+B$ \\
\hline & SP-2 & S. triostinicus strain CKM7 (EU635725.1) & - \\
\hline \multirow[t]{2}{*}{ Spiny bamboo } & SB-1 & S. triostinicus strain CKM7 (EU635725.1) & $A+B$ \\
\hline & SB-2 & Saccharopolyspora gregorii strain 4037-02-0614 (AY588271) & A \\
\hline \multirow[t]{2}{*}{ Cassumanar } & CS-1 & S. paradoxus strain HBUM174056 (EU841653) & A \\
\hline & $\mathrm{CS}-2$ & S. bikiniensis strain 13661V (EU741193) & $A+B$ \\
\hline Mango & MG-1 & S. lividus strain NBRC 13787 (AB184480.1) & $A+B+C+D$ \\
\hline
\end{tabular}

*Identified by partial 16S rRNA gene sequence comparison, only the highest similarity was shown.

**Designation of $A, B, C$ and $D$ were the same as shown in Table 1. 


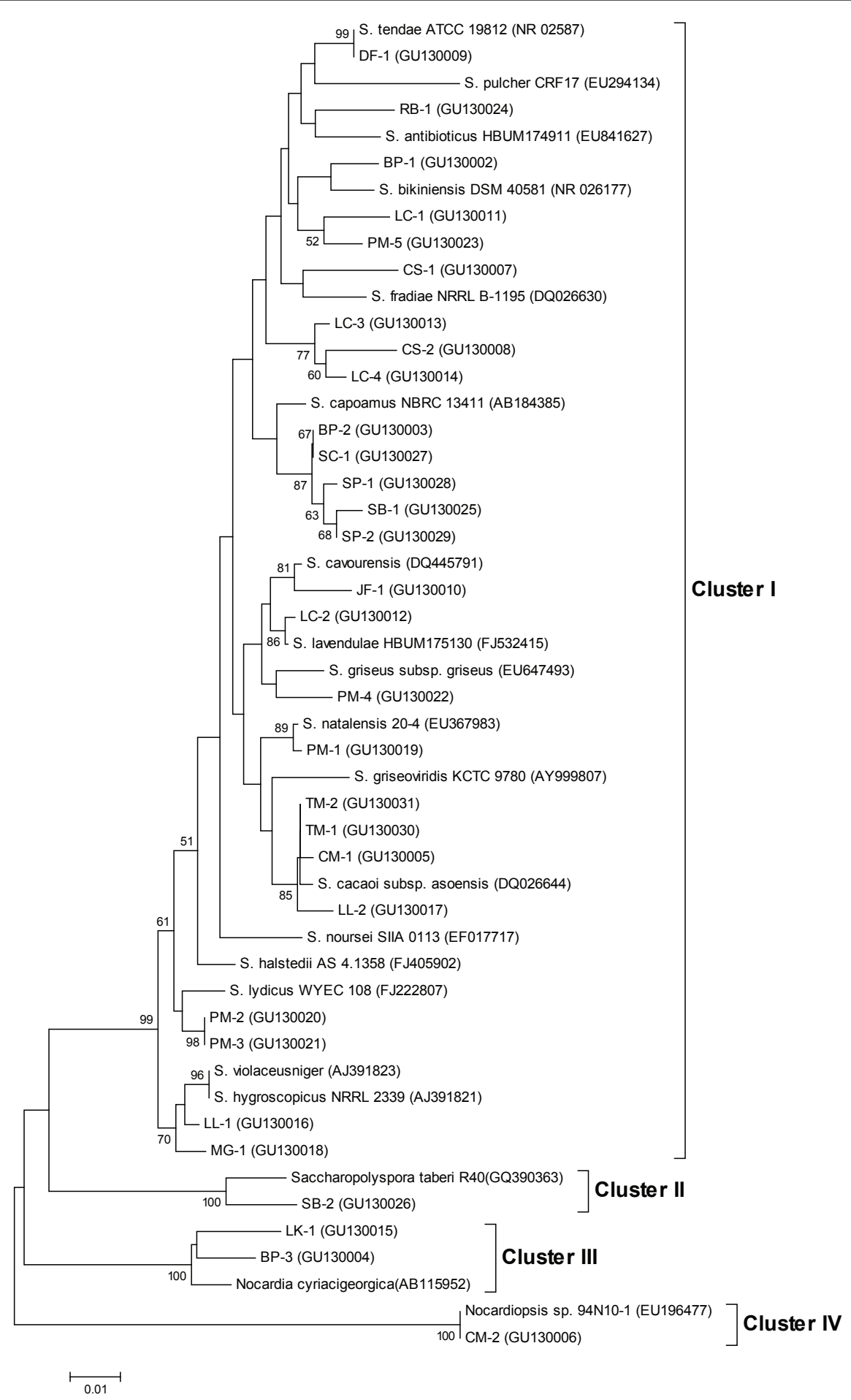

Figure 1 Neighbor-joining tree based on partial sequences of $16 \mathrm{~S}$ rDNA (500 bp) of $\mathbf{3 0}$ selected isolates. The numbers at the nodes indicate percentages of bootstrap support ( $n=1,000$ re-samplings). Bootstrap values less than $50 \%$ are not shown. The scale bar corresponds to 0.01 nucleotide substitution per site. 


\section{Determination of antifungal activity of 5 potent antagonistic Streptomyces strains}

The bioassay results for the 30 selected actinomycetes strains against the three pathogens and yeast identified 24 strains with antimicrobial potential especially against C. gloeosporioides DoA d0762 (Table 2). Furthermore, 5 Streptomyces strains (LC-1, LC-4, JF-1, SC-1, and MG-1) were found to be active against all indicator microorganisms (Table 2) and they were classified in distinct branches from each other (Figure 1). A previous report has indicated that taxonomically related strains might have some similarity in their metabolic pathways though certain strains were unique in their metabolic profiles [25]. Therefore these five strains, which are clustered in different groups, might produce different compounds with antifungal properties.

These five Streptomyces isolates were also active against conidial germination. As indicated in Table 3, they had antagonistic activity against C. gloeosporioides strains DoA d0762 and DoA c1060, and C. capsici strain DoA c1511. A clear zone, indicating inhibition of growth, ranging from $28-64 \mathrm{~mm}$ in diameter appeared around the colonies of the five isolates against the growth of C. gloeosporioides strain DoA d0762. Isolates JF-1 and MG-1 showed strong inhibition against three fungal strains with the inhibition zone ranging from 30 to $41 \mathrm{~mm}$ in diameter for C. gloeosporioides strain DoA c1060 and C. capsici strain DoA c1511. JF-1 and MG-1 displayed even stronger activity against the C. gloeosporioides strain DoA d0762 with an inhibition zone of greater than $60 \mathrm{~mm}$ in diameter.

The mechanism of antifungal antagonists can be due to the secretion of hydrolytic enzymes such as chitinase, $\beta, 3$ glucanase, chitosanase, and proteases [26] which degrade the fungal cell wall, or the secretion of antifungal compounds [27]. Streptomyces spp. from rhizospheric soil can protect roots by inhibiting the development of potential fungal pathogens; however, it

$\begin{aligned} & \text { Table } 3 \text { Antifungal activity of five Streptomyces isolates } \\
& \text { by the co-culture method against fungal conidial } \\
& \text { suspensions }\end{aligned}$
\begin{tabular}{cccc}
\hline Isolates & \multicolumn{4}{c}{ Activity against (mm) } \\
\cline { 2 - 4 } & $\begin{array}{c}\text { C.gloeosporioides } \\
\text { DOA d0762 }\end{array}$ & $\begin{array}{c}\text { C.gloeosporioides } \\
\text { DOA c1060 }\end{array}$ & $\begin{array}{c}\text { C. capsici } \\
\text { DOA c1511 }\end{array}$ \\
\hline LC-1 & 35.5 & 15.5 & 18 \\
LC-4 & 28 & 20 & 21.5 \\
JF-1 & 60.5 & 35.5 & 35.5 \\
SC-1 & 30.5 & 17 & 10.5 \\
MG-1 & 64 & 30.5 & 38.5 \\
\hline
\end{tabular}

The antifungal activity was measured after incubation for 7 days at $28^{\circ} \mathrm{C}$ and the distance indicated the zone of inhibition against the germination of indicator microorganisms. The inhibition zone included the diameter $(8 \mathrm{~mm})$ of the Streptomyces agar block. is not known whether the zone of inhibition, caused by the five Streptomyces strains, we isolated occurs as a result of extracellular hydrolytic enzymes or antifungal metabolites or the combined action of both. To determine whether the 5 selected isolates (LC-1, LC-4, JF-1, SC-1, and MG-1) with high antifungal activity produced antifungal metabolites, crude extracts were prepared by solvent extraction. Using a disk diffusion susceptibility test inhibition of mycelial growth was clearly observed in the presence of cell extracts after incubation for 7 days. It is possible that these strains are producing antifungal metabolites, since activity was retained in solvent extracted preparations [22,23]. Colony morphology of the five selected Streptomyces (strain LC-1, LC-4, JF1, SC-1 and MG-1) and activity of their crude extracts against C. gloeosporioides strain DoA c1060 are illustrated in Figure 2A and 2B, respectively. All five crude extract samples inhibited mycelial growth of the three anthracnose fungi (Figure 2B). Crude extract of MG-1 and JF-1 exerted a higher inhibitory activity over the other three crude extract samples as shown by larger inhibition distance as well as shorter outgrowth of fungal mycelia from the fungal agar block (Figure 2B). The antifungal activity of JF-1 colony as well as its crude extract against conidial growth of Colletotrichum spp. is shown in Figure 3A and 3B. Its crude extract shows strong inhibition against conidial suspension of C. gloeosporioides strains DoA d0762 (Figure 3, B-1).

\section{HPLC-DAD (High-Performance Liquid Chromatography with Diode-Array Detection) analysis}

Crude extracts from the 5 isolates were separated by HPLC and analyzed for their retention times and UVvisible properties. The results show that crude extracts from 3 strains (LC-4, SC-1, and MG-1) produced known compounds; strain LC-1 produced no significant peaks; however, the JF-1 isolate appeared to produce novel compounds (Table 4). The novelty of the secondary metabolites from strain JF-1 remains to be confirmed through purification and structural elucidation of the metabolites and these compound(s) are currently under investigation. From the analysis of the HPLC profiles it appears that the five isolates, which reside in different phylogenetic branches (Figure 1), produce different bioactive compounds (Table 4).

\section{Conclusions}

In summary, plant rhizospheric soil contains abundant actinomycetes species capable of producing different antifungal compounds. HPLC analysis of cell extracts revealed that one of the isolated strains (JF-1) has a high potential to produce novel bioactive compounds that were not present in our database. Purification and structure determination are essential for the further analysis 


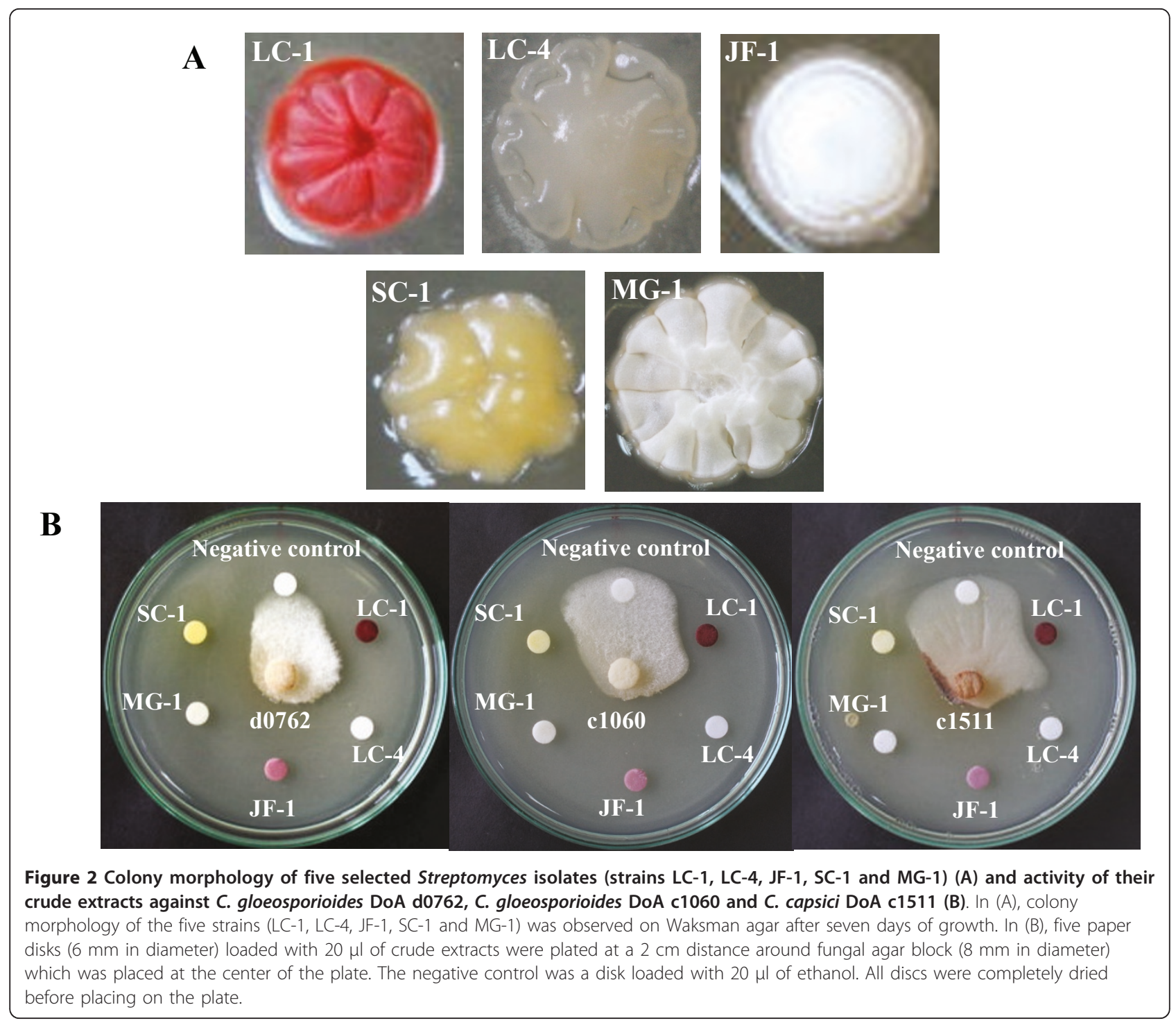

and application of these compounds for use in the control of Colletotrichum and anthracnose disease.

\section{Methods}

Indicator microorganisms and culture conditions

Colletotrichum gloeosporioides strains DoA d0762 and DoA c1060 and C. capsici strain DoA c1511 were obtained from Department of Agriculture, Ministry of Agriculture and Co-operatives, Thailand. Saccharomyces cerevisiae strain IFO 10217 was kindly provided by Dr. Chuenchit Boonchird, Department of Biotechnology, Faculty of Science, Mahidol University, Thailand. The fungi and yeast were incubated at $28^{\circ} \mathrm{C}$ and maintained on potato dextrose agar (PDA) or 301 medium $(2.4 \%$ starch, $0.1 \%$ glucose, $0.5 \%$ yeast extract, $0.3 \%$ meat extract, $0.4 \% \mathrm{CaCO}_{3}$, and $1.2 \%$ agar).

\section{Isolation of actinomycetes from soil samples}

Rhizospheric soils (39 samples) were collected from under fruit trees or plants in fruit orchards from Chanthaburi, Bangkok, Petchaburi, and Nongbualamphu provinces. Soil samples $(1 \mathrm{~g})$ were suspended in normal saline solution $(9 \mathrm{ml})$. The suspension was serially diluted to final dilutions of $10^{-4}, 10^{-5}$ and $10^{-6}$. Aliquots $(0.1 \mathrm{ml})$ of each dilution were spread on Pridham's agar (Pr) (1\% glucose, $1 \%$ starch, $0.2 \%\left(\mathrm{NH}_{4}\right)_{2} \mathrm{SO}_{4}, 0.2 \%$ $\mathrm{CaCO}_{3}, 0.1 \% \mathrm{~K}_{2} \mathrm{HPO}_{4}, 0.1 \% \mathrm{MgSO}_{4}, 0.1 \% \mathrm{NaCl}$ and $1.2 \%$ agar) and Water-proline agar (WA) (1\% praline and $1.2 \%$ agar) supplemented with $25 \mu \mathrm{g} / \mathrm{ml}$ nalidixic acid and $50 \mu \mathrm{g} / \mathrm{ml}$ cycloheximide to prevent growth of other bacteria and fungi, respectively. Plates were incubated at $28^{\circ} \mathrm{C}$ for 4-14 days. Isolated actinomycetes were further subcultured by incubating at $28^{\circ} \mathrm{C}$ and 


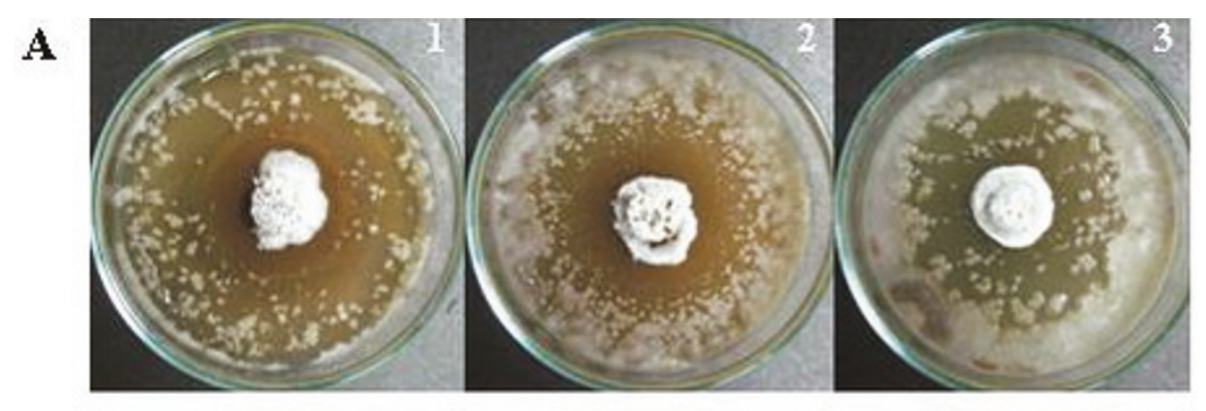

\section{B}

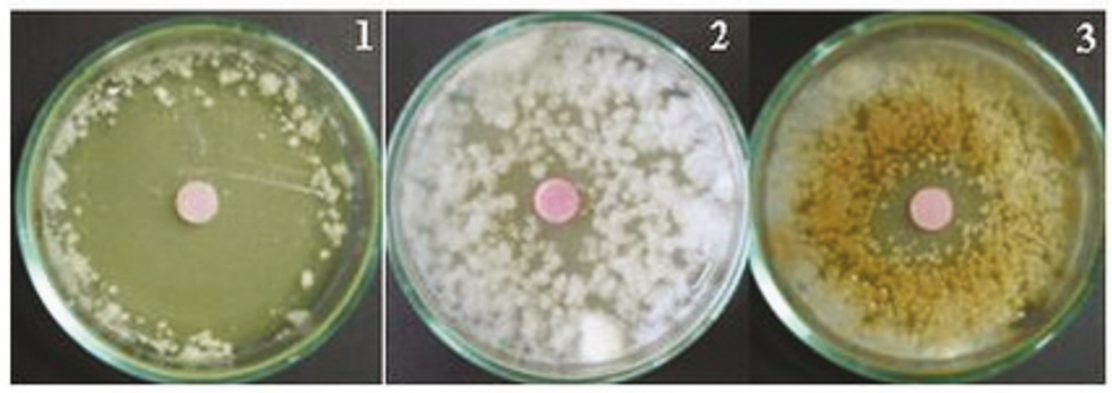

Figure 3 Antifungal activity of Streptomyces JF-1 (A) and its crude extract (B) against conidial suspensions of C. gloeosporioides DoA d0762 (A-1 and B-1), C. gloeosporioides DoA c1060 (A-2 and B-2) and C. capsici DoA c1511 (A-3 and B-3). The results were observed at day 7.

maintained on Seino's (1\% starch, $0.3 \% \mathrm{~N}-\mathrm{Z}$ amine typeA, $0.1 \%$ yeast extract, $0.1 \%$ meat extract, $0.3 \%$ $\mathrm{CaCO}_{3}$, and $1.2 \%$ agar) and Waksman agar slants $(1 \%$ glucose, $0.5 \%$ peptone, $0.5 \%$ meat extract, $0.3 \% \mathrm{NaCl}$, and $1.2 \%$ agar). The cultures on Seino's or Waksman agar were kept at room temperature and $4^{\circ} \mathrm{C}$ or $-20^{\circ} \mathrm{C}$, respectively. Strains were subcultured to fresh media every 2 months. For long-term preservation, conidial or mycelial suspension in $25 \%$ glycerol were kept at $-80^{\circ} \mathrm{C}$.

\section{Screening of antifungal activity by co-culture method}

Antifungal activity was evaluated as described previously [28]. The fungi and actinomycetes were grown on 301 medium at $28^{\circ} \mathrm{C}$ for 7 days. An agar block of indicator fungus was prepared using a sterile cork borer with diameter of $8 \mathrm{~mm}$, and placed at the center of the plate. Six agar blocks, each block containing a single actinomycete colony, were inoculated around the fungal block at a distance of $10 \mathrm{~mm}$ from the edge of the agar block.

Table 4 HPLC analysis of crude extracts

\begin{tabular}{ccc}
\hline Isolates & Peaks at retention time $(\mathbf{m i n})$ & Remarks \\
\hline SC-1 & $22.5(240,440 ;$ actinomycin $)$ & known \\
LC-1 & No significant peaks & no peak \\
LC-4 & $6.2(220,270 ;$ Trp-containing peptide $)$ & known \\
JF-1 & $24.0(250,285), 25.9(230)$ & unknown \\
MG-1 & $10.4(290,330 ;$ staurosporin $)$ & known \\
\hline
\end{tabular}

Note: The numbers in parenthesis indicate the wavelength in $\mathrm{nm}$.
The plates were incubated at $28^{\circ} \mathrm{C}$ and inhibition of mycelial growth was measured after 7 days [28]. For testing the inhibitory activity against yeast, $S$. cerevisiae was grown in $\mathrm{PDB}$ broth at $30^{\circ} \mathrm{C}$ for 2 days and a sterile cotton swab was dipped into this culture and spread evenly onto PDA plates. Agar blocks of seven-day-old cultures of isolated actinomycetes were placed on the PDA plate (six isolates/plate). After incubition for 2 days, the inhibition zone was measured. The five strains that showed antifungal activity were further tested for inhibition of conidial germination by inoculating a single agar block of each isolate onto an agar plate $(55 \mathrm{~mm}$ in diameter) previously spread with fungal conidia $\left(10^{5}\right.$ conidia/plate).

\section{Extraction and bioassay for antifungal activity}

Five strains (strain LC-1, LC-4, JF-1, SC-1 and MG-1) showing strong activity against all three indicator fungi were cultivated in $100 \mathrm{ml}$ of 301 broth at $28^{\circ} \mathrm{C}$ for 2 days in 500-ml Erlenmeyrer flasks. The pre-culture $(10 \mathrm{ml})$ was inoculated into $200 \mathrm{ml}$ of 301 medium in a 500-ml Erlenmeyrer flask, followed by incubation at $28^{\circ} \mathrm{C}$ for 6 days with rotary shaking at $150 \mathrm{rpm}$. After the cultivation, an equal volume of absolute ethanol was added to the entire culture. The mixture was shaken at $150 \mathrm{rpm}$ for 45 minutes and the organic layer was obtained by centrifugation. The cell-free supernatant was evaporated to half the original volume and then extracted with equal volume of ethyl acetate. The ethyl 
acetate-extract was evaporated and the residue was dissolved in ethanol $(1 \mathrm{ml})$. For bioassays, the extracts (about $0.2-0.4 \mathrm{mg} / 20 \mu \mathrm{l}$ ) were loaded onto a sterile filter disk (diameter $6 \mathrm{~mm}$ ). The disk was left at room temperature until completely dried. A blank disk loaded with $20 \mu \mathrm{l}$ of ethanol was used as negative control. The six disks were placed on the surface of agar medium around an agar block ( $8 \mathrm{~mm}$ in diameter) containing each indicator fungus. The inhibition zone was measured after further incubation at $28^{\circ} \mathrm{C}$ for 7 days.

\section{HPLC-DAD (High-Performance Liquid Chromatography with Diode-Array Detection) analysis}

Analytical HPLC was carried out with a Rainin Microsorb C18 column $(4.6 \times 75 \mathrm{~mm})$ on an Agilent HP1100 system with a photodiode array detector (200-600 nm). The flow rate was $1.2 \mathrm{ml} / \mathrm{min}$, and additional UV detection was measured at $254 \mathrm{~nm}$. The mobile phase used was a stepwise gradient of $\mathrm{CH}_{3} \mathrm{CN}-0.15 \% \mathrm{KH}_{2} \mathrm{PO}_{4}(\mathrm{pH}$ $3.5)(15 \%-85 \% \mathrm{v} / \mathrm{v})$. Chemical library analysis was performed by comparing the UV spectra and retention time of respective peaks to those of compounds in the database at Toyama Prefectural University, Japan.

\section{S rRNA gene sequence analysis for bacterial identification at the genus level}

Partial 16S rRNA gene sequences $(\sim 500 \mathrm{bp})$ from the isolates were determined from PCR-amplified fragments. The genomic DNA used as templates for PCR was prepared from single colonies grown for 4-5 days on Waksman agar plate using the boiling method [29]. The $16 \mathrm{~S}$ rRNA fragment $(\sim 500 \mathrm{bp})$ was amplified using universal primers UFUL (5'-GCCTAACACATGCAAGTCGA-3') and URUL (5'-CGTATTACCGCGGCT GCTGG-3') [30]. The PCR conditions consisted of an initial denaturation at $5 \mathrm{~min}$ at $94^{\circ} \mathrm{C}$ followed by 30 cycles of amplification $\left(94^{\circ} \mathrm{C}\right.$ for $30 \mathrm{sec}, 55^{\circ} \mathrm{C}$ for $30 \mathrm{sec}$ and $72^{\circ} \mathrm{C}$ for $\left.30 \mathrm{sec}\right)$ and an additional $7 \mathrm{~min}$ at $72^{\circ} \mathrm{C}$. The direct sequencing of PCR products was performed by dideoxy chain termination method using 3100-Avant Genetic Analyzer (Applied Biosystems), USA. The obtained sequences were analyzed for homology using BLASTN [31].

\section{Phylogenetic analysis of isolates}

$16 \mathrm{~S}$ rRNA sequences of 30 strains were aligned with $16 \mathrm{~S}$ rRNA sequences of other actinomycetes retrieved from the EMBL/GenBank database. Multiple alignments were performed manually using Clustal $\times$ [32]. Neighbor-joining phylogenetic tree and molecular evolutionary analyses were conducted using MEGA version 4 [33].

\section{Nucleotide sequence accession numbers}

The nucleotide sequences of 16S rRNA from the 30 isolates investigated in this study have been deposited in the GenBank database library under accession numbers GU130002-GU130031.

\section{Acknowledgements}

This work is partially supported by Center of Excellence for Agricultural Biotechnology, Science and Technology Postgraduate Education and Research Development Office (PERDO), Commission on Higher Education, Ministry of Education, and a research grant under the joint program in the field of Biotechnology between Japan Society for the Promotion of Science (JSPS) and Natural Research Council of Thailand (NRCT). We thank Dr. Laran T. Jensen, Mahidol University, for critical editing of this manuscript.

\section{Author details}

${ }^{1}$ Department of Biotechnology, Faculty of Science, Mahidol University, Bangkok 10400, Thailand. ' $\mathrm{MU}-\mathrm{OU}$ Collaborative Research Center for Bioscience and Biotechnology, Faculty of Science, Mahidol University, Bangkok 10400, Thailand. ${ }^{3}$ Center of Excellence for Agricultural Biotechnology (AG-BIO), Postgraduate Education and Research Development Office, Commission on Higher Education, Ministry of Education, Thailand. ${ }^{4}$ International Center for Biotechnology, Osaka University, Osaka 565-0871, Japan. ${ }^{5}$ Biotechnology Research Center, Toyama Prefectural University, Toyama 939-0398, Japan

\section{Authors' contributions}

Bl collected rhizospheric soil samples, isolated the cultures and tested their antifungal activities, performed the phylogenetic analyses, and wrote the manuscript. YI supervised and performed HPLC-DAD analysis. IL and TN participated on actinomycete isolation and crude extract preparation, respectively. WP was involved in research planning, supervised all analyses and participated in manuscript writing. All authors read and approved the final manuscript.

\section{Competing interests}

The authors declare that they have no competing interests.

Received: 20 August 2010 Accepted: 1 April 2011

Published: 1 April 2011

\section{References}

1. Than PP, Prihastuti H, Phoulivong S, Taylor PWJ, Hyde KD: Chilli anthracnose disease caused by Colletotrichum species. J Zhejiang Univ Sci B 2008, 9:764-778.

2. Freeman $\mathrm{S}$, Katan $\mathrm{T}$, Shabi E: Characterization of Colletotrichum species responsible for anthracnose disease of various fruits. Plant Dis 1998, 82:596-605.

3. Peres NAR, Kuramae EE, Dias MSC, Souza NL: Identification and characterization of Colletotrichum spp. affecting fruit after harvest in Brazil. J Phytopathol 2002, 150:128-134.

4. Pakdeevaraporn P, Wasee S, Taylors PWJ, Mongkolporn O: Inheritance of resistance to anthracnose caused by Colletotrichum capsici in Capsicum Plant Breeding 2005, 124:206-208.

5. Yakoby N, Zhou R, Kobiler I, Dinoor A, Prusky D: Development of Colletotrichum gloeosporioides restriction enzyme mediated integration mutants as biological agents against anthracnose disease in avocado fruits. Phytopathology 2001, 91:143-148.

6. Cho SJ, Lee SK, Cha LB, Kim YH, Shin KS: Detection and Characterization of Gloeosporium gloeosporioides growth inhibitory compound iturin A from Bacillus subtilis strain KS03. FEMS Microbiol Lett 2003, 223:47-51.

7. Yoshida S, Shirata A, Hiradate S: Ecological Characteristics and Biological Control of Mulberry Anthracnose. Jpn Agric Res Q 2002, 36:89-95.

8. Demain AL, Fang A: Emerging concepts of secondary metabolism in actinomycetes. Actinomycetologica 1995, 9:98-117.

9. Bérdy J: Bioactive microbial metabolites. J Antibiot 2005, 58:1-28.

10. Taddei A, Rodriquez MJ, Vilchez EM, Castelli C: Isolation and identification of Streptomyces spp. from Venezuelan soils: Morphological and biochemical studies. Microbiological Research 2006, 161:222-231.

11. Ilic SB, Konstantinovic SS, Todorovic ZB, Lazic ML, Veljkovic VB, Jokovic N, Radovanovic $B C$ : Characterization and antimicrobial activity of the bioactive metabolites in Streptomycete isolates. Microbiol 2007, 76:421-428. 
12. Rothrock CS, Gottlieb D: Role of antibiosis in antagonism of Streptomyces hygroscopicus var geldanus to Rhizoctonia solani in soil. Can J Microbiol 1984, 30:1440-1447.

13. Godfrey CRA: Agrochemicals from Natural Products New York: Marcel Dekker; 1995.

14. Qin Z, Peng V, Zhou X, Liang R, Zhou Q, Chen H, Hopwood DA, Keiser T, Deng Z: Development of a gene cloning system for Streptomyces hygroscopicus var yingchengensis, a producer of three useful antifungal compounds by elimination of three barriers to DNA transfer. J Bacteriol 1994, 176:2090-2095.

15. Raatikainen OJ, Paivinen TH, Tahvonen RT: HPLC separation and subsequent detection of aromatic heptaene polyenes in peat after treatment with Streptomyces griseoviridis. Pestic Sci 1994, 41:149-154.

16. Smith J, Putnam A, Nair M: In vitro control of Fusarium diseases of Asparagus officinalis $\mathrm{L}$. with a Streptomyces or its polyene antibiotic, Faeriefungin. J Agric Food Chem 1990, 38:1729-1733.

17. Hwang BC, Ahn SJ, Moon SS: Production, purification and antifungal activity of the antibiotic nucleoside, tubercidin, produced by Streptomyces violaceusniger. Can J Bot 1994, 72:480-485.

18. Trejo-Estrada SL, Paszczynski A, Crawford DL: Antibiotics and enzymes produced by biological agent Streptomyces violaceusniger YCED-9. J Ind Microbiol Biotechnol 1998, 21:81-90.

19. Crawford DL, Lunch JM, Whipps JM, Ousley MA: Isolation and characterization of actinomycetes antagonists of fungal root pathogen. Appl Environ Microbiol 1993, 59:3899-3905.

20. Holt JG, Krieg NR, Sneath PHA, Staley JT, Williams ST: Bergey's Manual of Determinative Bacteriology Baltimore: Williams \& Wilkins; 1994.

21. Nannipieri P, Ascher J, Ceccherini MT, Landi L, Pietramellara G, Renella G: Microbial diversity and soil functions. Eur J Soil Sci 2003, 54:655-670.

22. Barea JM, Pozo MJ, Azcon R, Azon-Aguilar C: Microbial co-operation in the rhizosphere. J Exp Bot 2005, 56:1761-1778.

23. Schimel JP, Hattenschwiler S: Nitrogen transfer between decomposing leaves of different N status. Soil Biol Biochem 2007, 39:1428-1436.

24. Anupama M, Narayana KJP, Vijayalakshmi M: Screening of Streptomycespurpeofuscus for antimicrobial metabolites. Res J Microbiol 2007, 2:992-994.

25. Zhang L, Demain AL: Natural products drug discovery and therapeutic medicine New Jersey: Humana Press Inc; 2005.

26. Yuan WM, Crawford DL: Characterization of Streptomyces lydicus WYEC108 as a potential biocontrol agent against fungal root and seed rots. Appl Environ Microbiol 1995, 61:3119-3128.

27. Khamna S, Yokata K, Pebery JF, Lumyong S: Antifungal activity of Streptomyces spp. isolated from rhizosphere of Thai medical plants. Int J Integrat Biol 2009, 6:143-147.

28. Bredholdt $H$, Galatenko OA, Engelhardt K, Fjærvik E, TErekhova LP, Zotchev SB: Rare actinomycete bacteria from the shallow water sediments of the Trondheim fjord, Norway: isolation, diversity and biological activity. Environ Microbiol 2007, 9:2756-2764.

29. Afghani B, Stutman HR: Polymerase chain reaction for diagnosis of Myeobacterium tuberculosis: comparison of simple boiling and a conventional method for DNA extraction. Biochem Mol Med 1996, 57:14-18.

30. Nilsson WB, Strom MS: Detection and identification of bacterial pathogens of fish in kidney tissue using terminal restriction fragment length polymorphism (T-RFLP) analysis of $16 \mathrm{~S}$ rRNA genes. Dis Aquat Org 2002, 48:175-185.

31. Entrez Nucleotide database. [http://www.ncbi.nlm.nih.gov]

32. Thompson J, Gibson T, Plewniak F, Jeanmougin F, Higgins D: The CLUSTAL_X windows interface: flexible strategies for multiple sequence alignment aided by quality analysis tools. Nucleic Acids Res 1997, 25:4876-4882.

33. Tamura K, Dudley J, Nei M, Kumar S: MEGA4: molecular evolutionary genetics analysis (MEGA) software version 4.0. Mol Bio Evol 2007, 24:1596-1599.

doi:10.1186/1756-0500-4-98

Cite this article as: Intra et al:: Identification of actinomycetes from plant rhizospheric soils with inhibitory activity against Colletotrichum spp., the causative agent of anthracnose disease. BMC Research Notes 2011 4:98.

\section{Submit your next manuscript to BioMed Central and take full advantage of:}

- Convenient online submission

- Thorough peer review

- No space constraints or color figure charges

- Immediate publication on acceptance

- Inclusion in PubMed, CAS, Scopus and Google Scholar

- Research which is freely available for redistribution

Submit your manuscript at www.biomedcentral.com/submit
C Biomed Central 